\title{
El espíritu acefálico y la imposibilidad de decirlo todo
}

\author{
Daniel Butti \\ Universidad de Buenos Aires \\ dabutti@yahoo.com
}

Catalogar a priori a Georges Bataille puede suponer cierta dosis de arbitrariedad, la que quizás sea necesaria para atreverse a encontrar en la obra de este filósofo, poeta, bibliotecario, místico o decididamente loco, como él prefería denominarse, los soportes conceptuales que permitan ubicarla claramente en una estantería del pensamiento contemporáneo.

Es conocido que recorrió variados caminos en su producción intelectual, incursionando en la poesía, el artículo documentalista, el relato erótico, el ensayo sociológico y hasta el manifiesto doctrinario. Pero paradójicamente quizás ninguno de sus escritos esté a la altura de lo que su obra, tomada como un todo, nos propone. De alguna forma, en Bataille sucede que las palabras, los estilos, no logran articular de una forma sistemática las ideas que se presentan, pudiéndose interpretar esto como la imposibilidad de decirlo todo, lo cual, tomado debido cuidado, puede ser uno de los rasgos más provocadores de su escritura para aquellos que percibimos la apertura de una posibilidad de pensar el Mundo por fuera de la tiranía del gobierno de las cosas.

Escribir desde Bataille entonces puede tornarse un acto sumamente riesgoso, en el que no tendría cabida el criterio de funcionalidad al que toda línea de investigación debe abonar. Para dar cuenta del sentido de esta búsqueda, ni las citas ni la indagación bibliográfica parecen poder aportar mucho, y entonces quedan a modo de decoración, para hacer más apacible la lectura; fundamentar con fechas y datos un pensamiento en constante tormenta es maniatar sus ideas bajo el supuesto rigurosismo del cientista. Bataille, por el contrario, provoca la idea de comunicación, pero ésto se traslada a un texto recién cuando éste niega al sí mismo del autor, a las particularidades de los lectores, en provecho de la lectura.

La filosofía bateilleana, lejos de la actitud contemplativa tradicional, supone un vitalismo en el que el hombre se inmola para acceder a lo sagrado, y es el mismo Bataille el que poniéndolo en práctica da cuenta que el erotismo, el exceso, la transgresión, son sendas que conllevan incondicionalmente a la muerte. Comunicación y muerte puestas al encuentro, es el erotismo el que emerge iluminándolo todo, y es que si bien el hombre no está limitado al órgano del placer, este inconfesable órgano le entrega el secreto de la existencia (Bataille, 1977). Hurgar entonces en esa búsqueda, en las alianzas y las filiaciones, en la comunidad imposible de filósofos místicos que buscan aquello vedado para la memoria del hombre. Si en particular la conducta del sacrificio, la menos clara, pero la más divina y la más común, deja de estarnos cerrada, la totalidad de la experiencia humana se nos entrega (Bataille, 1975) El pensamiento entonces deviene fiesta y... En la fiesta están incluídos: orgullo, desenfrenada 
alegría; la burla de toda clase de seriedad y de probidad burguesas; una divina afirmación de sí mismo hecha de plenitud y de perfección animales (Nietzsche, 2001).

Hay una constante tensión en la producción teórica de Bataille que tiene como nudo lo indecible. Su arquitectura filosófica -atravesada por la economía general, la dialéctica hegeliana y el vitalismo nietszcheano- tiene como piedra angular la angustia del hombre ante la imposibilidad de respuesta última a su existencia, el terror ante la disolución de la verdad que se insinúa en Nietzsche y se palpa luego de la primer Gran Guerra. Y es su vida la que confronta con lo imposible, al pretender resolver esta respuesta siéndolo todo, lo que nos anuncia en su Sobre Nietzsche:

El gusto que tengo en saberme y en ser risible no puede ir, empero, tan lejos que me lleve a desorientar a quien me lee. El problema esencial debatido en este libro desordenado (y debía serlo) es el que Nietzsche vivió, el que su obra intentó resolver: el del hombre total. (Bataille, 1972)

Esta obra, que escribió con la voluntad de publicar en el centenario del nacimiento del filósofo de Sajonia $^{1}$ (15 de octubre de 1844) -y que junto con La experiencia interior y El culpable conformarán lo que el propio Bataille denominara su Suma Ateológica-, da cuenta del intento vitalista de Bataille en el que asume dejar de lado toda rigurosidad teórica por el relato de una experiencia vivida, una experiencia de veinte años, a la larga cargada de espanto en sus propias palabras. Nietzsche escribió "con su sangre": quien le critica o, mejor, le sufre, no puede hacerlo sino sangrando a su vez (Bataille, 1972).

Con relación a ello Tomás Abraham destaca en él su sufrimiento por no serlo todo (Abraham, 1987). La muerte del absoluto es la muerte del ser propone el filósofo argentino como punto de partida para su argumento, retomando palabras del francés en Teoría de la religión (Bataille, 1975). En un mundo en el que lo absoluto se ha retirado, sufre el ser la soledad de la nada se lamenta Bataille, anunciando la angustia postmoderna.

El problema es tal ya que resulta insoportable la ausencia de una verdad única, dado que tanto el relato religioso es racionalmente impugnado por la racionalidad moderna -adviniendo en palabras de Heidegger una imagen de mundo (Heidegger, 1995)- como el propio discurso auto legitimador de la racionalidad moderna comienza a encontrarse con sus limitaciones para erigirse como paradigma total. Ya la reflexión de la conciencia moderna sobre sí misma había comenzado a dar cuenta del problema de la representación idónea para el decir de la verdad, y es en esta búsqueda que emerge la terrible sospecha que no hay representación posible de ésta, sino estrategias de seducción.

Ese Ángelus Novus de la pintura de Klee al que Benjamin percibe como la cabal representación de la ideología del progreso (Benjamín, 1971) se cobija en la materialidad expresiva de la novedad, en la fascinación lustrosa de lo efímero. De alguna forma, si la escritura moderna inicia una aventura que reivindica para sí la materialización de un acontecer puro en sí mismo (Rodríguez García, 1994) en Bataille ya es posible percibir los rasgos de esa post modernidad que no sólo pone en tensión los significados, sino hace estallar los significantes, transgrediendo el límite de lo decible.

1 "Lo escribí de febrero a agosto, esperando que la huida de los alemanes hiciese posible su publicación" relata en su introducción. 
Es en esta transgresión que el francés busca la verdad, o según se lo entienda, serlo todo, sin escaparle a sus consecuencias, ya que sabe vana (la) empresa buscar un desvío: es preciso elegir, de un lado un desierto y del otro una mutilación (Bataille, 1972).

No puedo existir totalmente más que superando el estadio de la acción de algún modo. Si no, seré soldado, revolucionario profesional, sabio, pero no "el hombre completo". El estado fragmentario del hombre es, en el fondo, lo mismo que la elección de un objeto. Desde el punto en que un hombre limita sus deseos, por ejemplo, a la posesión del poder en el Estado, actúa, sabe lo que debe hacer. Poco importa que fracase: desde el comienzo inserta provechosamente su ser en el tiempo. Cada uno de sus movimientos se hace útil. Se le ofrece la posibilidad, en cada momento, de avanzar hacia el fin elegido: su tiempo se convierte en una marcha hacia ese fin (a tal cosa se llama habitualmente vivir). Y lo mismo si tiene por objetivo su salvación (Bataille, 1972)

La idea que postula no sólo condena al hombre al sufrimiento (o al mal, ya que incluso la salvación puede ser tomada como actividad alienante) sino que toda acción haría del hombre un ser fragmentario. Es imposible mantener en el ser al carácter total más que rehusando a obrar, o por lo menos negando la eminencia del tiempo reservado para la acción. El arte, en cambio, constituye un pequeño dominio libre fuera de la acción, que paga su libertad con la renuncia al mundo real. Y por este sustraerse al reino de la cosa, esa entrega sin finalidad productiva, toma su esencia. Rescatando el tiempo improductivo, vivido como definiría Bergson (Bergson, 1966), esa existencia no se aleja tanto de su completud.

Serlo todo, ser arma defensa, cual fortaleza ante la urgencia; de ataque, en la construcción de un pensamiento en el debate ante los adversarios. Ser un apóstata, un vicioso, un cuerpo entregado a los excesos. Ser una sensibilidad delicada que cultiva una erudición psicótica. Ser cura, pornógrafo, bibliotecario, subversivo, místico, poeta, disoluto, filósofo. $Y$ sucumbir ante la imposibilidad de serlo. Para Bataille en cambio la filosofía era un acto de vida, ni manuales ni recetas; un acto vital, una experiencia con el cuerpo. Una carcajada frente a la racionalidad objetivante. No es otra la concepción de la filosofía para Nietzsche, aunque éste afirmara tener un miedo terrorífico a que un día se me tilde de santo (Nietzsche, 1987) de alguna forma presintiendo lo vulnerable de algunas actitudes ante las costumbres instituidas. Y quizás aquí valga detenerse a recordar el mote de místico que le endilgara Sartre ${ }^{2}$ cuando publica en 1943 La experiencia interior.

Si bien la comunicación se da entre la esfera de lo sagrado a la de lo profano a través de ritos, la búsqueda de la postulación bateilleana es para romper con ellos, pero esta ruptura no es la de la desdivinización racionalista, sino la de la transgresión y el exceso que remiten a un nuevo despliegue de los mismos. Las prohibiciones, más que vedar el acceso a la comunicación, lo auspician, alzando entre estas esferas una barrera que las preserva de la catástrofe -en polinesio, a las prohibiciones las llaman tabú, y se refiere a la misma sustancia que hace innombrable al dios judío-. Pero Bataille lamenta que las manifestaciones arcaicas de lo sagrado se nos aparezcan como jeroglíficos que solo desciframos formalmente, no experimentamos. Si el sacrificio, la menos clara y más divina conducta deja de estarnos cerrada, la totalidad de la experiencia humana se nos entrega (Bataille, 1997). En su mirada, el éxtasis del sacrificio se confunde con el extremo goce sádico.

\footnotetext{
${ }^{2}$ Ante la publicación de La experiencia interior por parte de Bataille en 1943, Sartre publica un violento artículo criticándolo titulado Un nuevo místico.
} 


\section{Decirlo todo}

Si acatáramos la paradójica sentencia del Tratactus de Wittgenstein, "de lo que no se puede hablar mejor callar", seguramente nuestro ámbito se reduciría al silencio absoluto. La sentencia adquiere un sentido único, particular, en cuanto exige un trato más respetuoso del misterio, impone una medida, llama el pensar a la mesura. Pero a la vez habilita a pensar que el lenguaje que nos propone es el de la experiencia muda, donde las personas ya no precisen de palabras. Nuevas formas sociales no necesitarán comunicación verbal alguna -afirma el poeta Paul Engelmann a partir de la teoría de su amigo- No se comunicarán los ideales mediante intentos, inevitablemente falsificadores, de describirlos, sino sólo mediante modelos de vivir (Engelmann, 1967). La comunicación entendida como un uso competente de un lenguaje, y éste entendido como un sistema de signos, se pone totalmente en entredicho cuando lo comunicable deja su carácter de abstracción para erigirse en común-unión, experiencia íntima del encuentro de los hombres. Es que también en Wittgenstein la raíz más profunda de su inquietud emerge luego de atravesada una experiencia mística: Ella me empujó a chocar contra los límites del lenguaje, de igual modo que a llevado a chocar con ellos a todas aquellas personas que alguna vez han intentado hablar o escribir sobre lo sagrado o la religión. Este chocar con los límites de nuestra jaula es una empresa que no tiene ningún porvenir (Wittgenstein, 1991). Percibir lo oscuro como oscuro, ir a las penumbras sin amuletos ni brújulas, captarlo hasta el estremecimiento y el terror; tal parece el compromiso de Bataille, que se inmola a sabiendas de lo inútil de su empresa.

A través de los artilugios de la letra, el francés ejerce una torsión cruel, transgrede nuestros esquemas morales y espistemológicos. Los trata como un ser que ofrece en sagrado sacrificio. La ambivalencia del bien y del mal es sospechosa y por tanto digna de investigación. $Y$ no es en los tratados de ética clásicos donde encontramos pistas para ello, pues en éstos ya se han prejuzgado los hechos desde siempre, a priori, mediante las consabidas calificaciones morales. La verdad, lo que termina siendo llamado de esta manera, no resulta sino una ilusión más, una máscara que el destino ha hecho inevitable. Y como la verdad siempre está ligada a la experiencia, hay verdades que requieren la transgresión, el traspaso de nuestros valores, que algo sea aniquilado en nosotros mismos. Podría ser uno de los principios del pensamiento de Bataille, porque se mueve en una espiral constituida de paradojas donde lo posible nace de lo imposible, el erotismo de la muerte, la experiencia mística de una ateología y la economía del gasto y del exceso.

Bataille postula en su búsqueda que el hombre no debe encerrarse en los límites de la razón, debe reconocer una parte soberana, irreductible, que escapa de éstos. En su intento de delimitación conceptual, define la soberanía como el reino milagroso del no saber. De allí despliega no sólo una indagación en las costumbres arcaicas o indígenas, sino hasta su delirante intento de provocar un sacrificio humano en plena Plaza de la Concorde. Y es que más allá de lo anecdótico, la angustia que supone el deseo de comunicar solo se resuelve en la muerte o en el sacrificio, cuando en un fugaz momento le permite al hombre unirse al ser de su divinidad que la muerte ha puesto en juego al mismo tiempo (Bataille, 1972).

La transgresión es la entrada a ese territorio soberano, la actitud que reconoce los límites pero justamente en el reconocimiento los rompe. La fiesta es el evento posible en el que emerge esa experiencia, cuando el frenesí desbordante anula toda diferencia; el erotismo es el campo de batalla donde el goce anula lo otro; la experiencia interior es la que permite, a través de la meditación, acceder al éxtasis místico. Esa búsqueda se sostiene al percibir que esas leyes, que el hombre se 
impone y gobiernan su actividad, están ante todo para afrontar lo inexplicable de la muerte y la sexualidad. Esta idea, que formulará explícitamente en Las lágrimas de Eros, ya venía desarrollándose insistentemente desde su Historia del Erotismo, pensada como continuación de La noción de gasto y segundo volumen de La parte maldita ${ }^{3}$.

\section{El decir de la Pasión verdadera}

No se debe desatender que la búsqueda de Bataille peregrinó principalmente por los caminos de la escritura. La expresión de esa respuesta última, pero también el tesón kabalístico ${ }^{4}$ de explorar en múltiples técnicas y géneros. No es un problema formal, de mano izquierda, como encontramos en Apollinaire, sino de entrega apasionada. No olvidemos su protagonismo en múltiples proyectos editoriales: Verdadero pulmón de revistas como Arethusa, Documents, Revue Philosophique, La critique sociale, Contra Attaque, Acephale, Critique, graves problemas de salud ${ }^{5}$ le impiden concretar el proyecto de editar Genèse, una publicación dedicada a la sexualidad.

Pero aquí nos referimos no a su capacidad productiva, sino a la necesidad de decirlo todo, apasionadamente, por todos los medios y estilos; cruzando filosofía en sus relatos eróticos - ¿deriva sadiana?- o poesía en su análisis teórico -¿deriva nietzscheana?-

En palabras de José Luis Rodríguez, Bataille recupera la esperanza en el poder del decir de la Pasión verdadera (Rodríguez García, 1994). Y es que ante la evidencia de la imposibilidad de probar racionalmente la existencia de una verdad -a menos que determinemos normas eternas y absolutasy en el convencimiento de que tanto las normas tradicionales como la racionalidad moderna son las que enmascaran los discursos erigiéndose como suprema autoridad, el francés apuesta a la obra literaria como posibilidad de emergencia de lo soberano. Hacer obra literaria entonces es darle la espalda al servilismo. Si el hombre de arte soberano es capaz de comunicar con cualquier otro ser humano, es porque tiene el valor de desnudarse ante él, amorosamente, hasta el extremo de la risa y de las lágrimas, del fulgor y de las cenizas de la inmolación y la impotencia. Sus palabras nos sirven para comunicarnos con el otro, pero poniéndolo en el mismo abismo, y en este sentido, el lenguaje poético es lenguaje de comunión. Aquí la soberanía requiere el impulso del corazón y la lealtad, porque se da en la comunicación, lealtad sin la cual se deshace el edificio de la soberanía (Bataille, 1975).

Bataille también confía en la efusión de la meditación, y la más violenta de ellas es la poesía, ya que la poesía expresa únicamente orden en las palabras gracias a cierto derroche de energía. La poesía es la voluntad de hacer emerger lo indecible, donde también se materializa la transgresión, la parte maldita que no encuentra palabras. Recién allí la literatura es comunicación, ya que niega al sí mismo del autor, a las particularidades de los lectores, en provecho de la lectura. En este sentido, el erotismo

${ }^{3}$ El erotismo finalmente se publicará en 1957 y fue tempranamente editado en castellano por Sur en 1964.

${ }^{4}$ En el sentido que le da la tradición judía a este concepto místico. Sólo recordar la relación de amistad que unía a Bataille con Benjamin, quien por entonces estaba introduciéndose en ese saber por medio de Gershom Sholem, lo que puede establecerse a partir de la lectura de su correspondencia con Adorno. Cf. Adorno, Theodor y Walter Benjamin; Correspondencia 1928/1940, Trotta, Madrid, 1998.

${ }^{5}$ Bataille sufrió desde 1942 ataques de tuberculosis pulmonar, y entre otras dolencias, en 1952 le diagnostican arteriosclerosis cervical. 
también es lenguaje -comunicación, himno- cuando niega al sí mismo del amante en función del éxtasis de los sentidos. Comunicar, habrá quedado claro, no es aquí intercambio ni instrumentalidad. No hay intercambio ni en el goce apasionado ni en la muerte, sino un orden de lo sagrado. Y la enigmática metáfora poética con la que el lenguaje nos define al orgasmo -la pequeña muerte- abre las puertas para tejer un reenvío a lo místico aún latente en los hombres.

El éxtasis erótico es entonces comunicación en cuanto no hace sino aniquilar. La comunicación que hay entre ambos no significa que cada uno encuentra su ser en el ser del otro, sino que lo único que ambos encuentran son sus heridas. El erotismo es, creo yo, la ratificación de la vida hasta en la muerte (Bataille, 2001). La sexualidad reenvía a la muerte. Pone en juego al que se reproduce. El fundamento de la efusión sexual es la negación del aislamiento del yo, que solo conoce éxtasis extendiéndose, trascendiéndose en el acto amoroso, donde se pierde la soledad del ser. El tormento del amor desencarnado es cuanto la muerte aproxima y hiere a los que el amor une.

Lúcidamente señala Jacques Derrida (Bataille, 2001) que no se trata en Bataille -cuando llega a lo que podríamos llamar los extremos de la posibilidad: el silencio o la muerte- de un discurso otro, sino de que el atisbo de lo irreductible podría darse en todo discurso si se acepta el desafío a sondear lo absoluto. Y entre ellos, la poesía, por ese mismo deseo de totalidad plena, ocupa un sitio primordial. En verdad, la sociedad actual es vulgar, hecha de fugas del hombre ante sí mismo, y se disimula bajo un decorado. Pero la poesía que evoca esa sociedad no se limita a describirla, es su negación, dice Bataille y desechando ese estado de cosas, el triunfo de lo profano, reivindica lo sagrado. Tal vez estas afirmaciones podrían leerse en clave esotérica, como un desasimiento de la circunstancia espacio-temporal, pero su modo de no desentenderse sino de encarar la cuestión desde su compleja perspectiva se hace notorio, por ejemplo, en su Carta a René Char sobre las incompatibilidades del escritor (Bataille, 2001) cuando, para oponerse a la esclavitud de la literatura al mundo de lo útil, apela directamente al momento histórico, al reclamar para el escritor una fidelidad total a su palabra y a los límites a que ella lo lleva, y al discutir con agudeza las concepciones sartreanas del compromiso y, sobre todo, de la elección.

\section{El espíritu acefálico y el legado de la época}

Cabe detenerse aquí para puntualizar que la influencia de lo heterológico y de las inquietudes del Colegio de Sociología llegarían hasta el Río de la Plata vía Roger Callois. Y es que justo cuando esa suerte de cenáculo esotérico-político-filosófico motorizado por Bataille e integrado entre otros por Callois, Michel Leiris y Pierre Klossowsky estaba desarrollando su primer programa de actividades, la circunstancia de la guerra suspende el proyecto, al menos en Francia... ${ }^{6}$.

Callois, que había viajado hacia 1939 a Buenos Aires, y vinculado con las tertulias eruditas del grupo Sur, prosiguió con el impulso organizando los Debates sobre temas sociológicos, y continuando en relación epistolar con Bataille, quien por ese entonces se retira en la escritura de La experiencia interior y en el cultivo de su amistad con Blanchot. En París la lucha era contra el nazismo que

\footnotetext{
${ }^{6}$ Según consta en el programa de actividades del Collège de Sociologie sacrée, Callois desarrolló la exposición Les sociétés animales el 19 de diciembre de 1937. Las previstas para el 19 de febrero, sobre Le pouvoir, así como la del 19 de marzo de 1938, sobre Confréries, ordres, sociétés secrètes, eglises, fueron dictadas por Bataille debido a problemas de salud de Callois, quien luego partió hacia Buenos Aires.
} 
ocupaba las calles. Bataille, además debía luchar contra la tuberculosis, y aún así su energía estaba puesta en esa otra disputa -épica vista desde hoy día- en torno a la significación del legado de Nietzsche. Las conferencias que dará congregarán entre otros a Camus -con quien había mantenido una agria polémica sobre la condena a la U.R.S.S.- Simone de Beauvoir, Blanchot, Danielou, Hyppolite, Klossowski, Leiris, Paulham, Merleau Ponty y Sartre, este último retractándose de su apresurado juicio sobre la seriedad de la búsqueda bateilleana.

En Buenos Aires, en cambio, la labor de Callois se erigió vital en la preservación de ideas, corrientes, y personas. A las oficinas de la editorial Sur -un amplio apartamento en el lujoso Barrio Norte porteño donde Callois residió varios años- se dirigía cuanto intelectual huído del terror de la guerra hubiera por las Pampas. A la sazón, las labores del francés en esta época también le permitieron cultivar ese intercambio, ida y vuelta postulado por Victoria Ocampo, ideóloga más que mecenas. Y será en la postguerra cuando Callois realice la introducción de toda esta corriente -Cortázar y Borges entre otros- a una Europa agobiada de pesimismo. Borges lo homenajea en una de sus más sugestivas ficciones: Tlön, Uqbar, Orbis Tertius (Borges, 1957) haciendo referencia a una comunidad secreta de intelectuales que logran poner en circulación un tomo apócrifo de la Encyclopaedia Britannica en el cual se formula la existencia del místico lugar de Tlön. El relato, bella excusa para la deriva filosófica a la que nos acostumbra Borges, tiene otro homenaje, más alusivo a Bataille, -pero para no perder la flema, situado en una nota al pié- y en el que da cuenta de los postulados de la iglesia de este mundo oculto, diciendo que todos los hombres, en el instante sagrado del orgasmo, son el mismo hombre. $Y$ mueren.

Ezequiel Martínez Estrada y Héctor Murena serán quizás las variantes más inquietantes de esa heterología en el acto.

Los americanos tenemos desde antes que nadie y con mayor intensidad la experiencia de la desuniversalización. En este ámbito oscuro y caótico, la voluntad se ve en cada momento llamada a actuarconvocada a librar su épica ante la tierra, sin poder encerrarse en el racionalismo ni abandonarse al irracionalismo. Este mundo crudo, libre de teoría, es la situación que Nietzsche pedía para que la razón hiciera frente a su verdadera prueba para fundar una filosofía viva (Murena, 1950).

Este pecado original de América Latina señalado por Murena no busca en su meditar la restitución a un todo armónico, sino intenta ser una coartada ateológica, abyecta, violenta, distorsiva. Primer traductor al castellano de Jünger, Simmel, Benjamin y la escuela de Frankfurt, así como profundo lector de Nietzsche, Murena sostenía que introducir la explicación por el mito es para el intelectual de la misma eficacia que para el militar. Pero esta afirmación no desconoce la importancia de la dimensión lo sagrado en la com-prensión del mundo.

El derroche y el erotismo presentes en el cubano Lezama Lima, que escribe sobre los Límites de la literatura (Lezama Lima, 1947), así como la arracionalidad del poeta Oswal de Andrade en Río de Janeiro, y su processo de remastigaçao que reenvía a la fiesta antropófaga, donde el hombre se come al ser, son deudores del espíritu bateilleano. Quizás más sugestiva sea la Experiéncia $n^{\circ} 2$, un ensayo de sociología sagrada escrito ya en 1931 por Flavio de Carvalho, elaborado a partir de desafiar el tabú en una procesión de Corpus para luego analizar la reacción de la masa. Carvalho, que conocía a Callois desde un congreso en Praga en 1934, estaba muy al tanto de lo que ocurría tanto en París como en Buenos Aires, y su convencimiento en esa búsqueda era tal que cuando la 
policía le clausura violentamente su Teatro da experiencia estaba montando una pieza acefálica: $\mathrm{O}$ bailado de deus morto.

Martínez Estrada tampoco ignoraba los escritos de Bataille, en particalar los publicados sobre Nietzsche en el centenario del filósofo, que le servirían de inspiración a su artículo sobre el alemán que vió la luz en 1947. Pero es más enigmática la relación que se abre entre la inquietud que comienza a desarrollar en la década del '30 y que culminará con la publicación de La cabeza de Goliat (Martínez Estrada, 1940) el texto más incisivo, esclarecedor y actual sobre la argentinidad. Cómo leer la acefalidad de Martínez Estrada sino es como la experiencia de un verdadero emigrado en su tierra, alguien que escribe desde la polis contra el Estado, impugnando centro y sistema, demandando el degüello de toda jerarquía, la negación de todo lo existente (Martínez Estrada, 1950).

Para poner en contexto estas afirmaciones habría que recordar que los estudios de Callois sobre el mimetismo nacen del Corydon de André Gide, y más precisamente de la afirmación de Henri Bergson según la cual la sexualidad humana actuaría tanto por anagénesis, principio económico de la acumulación, como por catagénesis, o sea por derroche y disipación. Guide, que obviamente desconoce a Freud y Bataille, afirma que si el sexo femenino es el de la previsión fisiológica, el masculino es el de la dépense luxuese, mais improductiva (Guide, 1951) y así como su obra podría leerse como un manifiesto trágico (busca ser la voz de la homosexualidad para llegar a la conclusión que esa voz carece de materialidad, que es sólo una posición de sujeto) encontramos para esa misma época que Lacan, asistente a las lecciones del Colegio de Sociología sagrada, propone otro estatuto para la interpretación -rompiendo la tradición de la psiquiatría- en su tesis De la psicosis paranoica en sus relaciones con la personalidad, donde caracteriza al discurso paranoico como una sintaxis original en estrecha vinculación con el problema de estilo. Sin entrar en los tecnicismos de la psicología, interesa destacar que para Lacan el problema de la paranoia es de comprensión, en tanto con-prenderla a otras manifestaciones posibes de la personalidad, como comprenderla en cuanto interpretarla, es decir, volver su discurso inteligible para otro sujeto. En el discurso paranoico Lacan supo observar la regresión de lo humano en lo animal, y es esta la clave que articula su trabajo al Colegio, ya que conviene observar que esta teoría de la subjetividad, que connota una teoría de la expresión y no de la existencia, emerge con la violencia pulsional del juego. De hecho Lacan señala en el campo de la teoría psicoanalítica lo que es lugar común en el arte: que las rupturas más fecundas suelen ser impulsadas por teorías aparentemente débiles, mientras es común que los programas más coherentes, por su manifiesta metafísica, se revelen inconsistentes o estériles.

Esta paradoja, que tensiona teoría y terror, enlaza el rien acefálico de Lacan con su contrapuesto, el neant positivo de Sartre, pero aquí es necesario volver a dar otra vuelta de tuerca para recordar que esa obra magistral de Sartre, El ser y la nada, nace como réplica a la propuesta emblemática presentada en el Colegio de Sociología por Bataille y a la teoría de la fiesta desarrollada en este ámbito por Callois. En efecto, en Carta a Castor (Sartre, 1986) confiesa que acaba de hacer una teoría sobre la guerra y la moral inspirada en la crítica de la teoría de la fiesta de Callois, a su vez blanco de la crítica de Lacan. Estas dos maneras de interpretar la transgresión (la fiesta y la guerra) que nos conducen a dos formas diferentes de negatividad -y que Klossowski analizara en otra obra escrita a cuatro manos con Bataille, Sade mon prochain (Klossowsky, 1970)- reaparecerán en los retornos ultramarinos del College de Sociología. 
En efecto, así como de la fiesta de Callois, o de lo sagrado y el erotismo de Bataille cada uno oyó lo que quiso o pudo (Lacan la acefalidad del deseo, Sartre la positividad del neant, Foucault la positividad del poder) la lectura de lo americanista bateilleano tendrá divergentes vertientes. Y más allá de las funcionales interesan las perspectivas heterológicas. El que más apunta en esa dirección es el ex martinfierrista Eduardo González Lanuza, que festeja que América sea un país de mulatos, porque por serlo es donde la idea de unidad cultural, que suma aquellos cuatro elementos de Valéry la armonía griega, la norma romana, la fé cristiana y el honor celta- con el añadido de la fiesta y lo heterológico, se va a realizar totalmente. Pero justamente por apostar a la fusión como un todo, como la vuelta al dominio de lo totalizante, es que Lanuza va a subrayar lo irrealizable de ese esfuerzo.

\section{Excursus final: El amor}

Bataille ha abierto caminos al pensamiento escribe Michel Foucault en el Préface à la transgression ${ }^{7}$ (Foucault, 1963). No es una frase laudatoria la que pretende ${ }^{8}$ sino la incitación al acto. Pensar en tanto meditar es el más improductivo de los gestos. Suspende el trajinar y nos entrega al cuestionamiento último del ser, puesto en juego.

Pensar entonces Bataille; y no en -el manido recurso biográfico de soterradas citas- ni a través como herramienta de lucha, arma en el campo de batalla de las lecturas del mundo- sino pensar desde. Y entregarse a la experiencia de lo sagrado en el desenfreno y el exceso; en la transgresión oscura del apóstata que hace de la vida el problema, no la solución; en el sacrificio.

Pero hay algo que en Bataille no cobra densidad -debido sobre todo por su obsesión por lo bajo, lo oscuro- y es el sentimiento del amor. Que también suspende el carácter productivo del mundo, cualquier criterio de utilidad, es desgarrador y en exceso conduce a la muerte. Que no es el erotismo queda de mal gusto reafirmarlo, por lo redundante. $Y$ es que no se trata del goce apasionado de los cuerpos, sino del desenfreno de un sentimiento también violento, que no tiene por qué poder ser vinculado gratuitamente a lo sublime y a lo alto: El amor del ser mortal. Ese auténtico don, que es la entrega de sí mismo al otro, también abre la puerta a lo sagrado. $Y$ en la esencia que se devela el ser emerge, desprovisto de todo mal, sacrificado.

\section{Referencias}

Abraham, Tomás (1987) Pensadores bajos. Buenos Aires: Catálogos.

Bataille, Georges (1970-1988) Oeuvres Complétes, -12 vol- [Presentación de Michel Foucault; edición de D. Hollier, T. Klossowski, M. Leduc, H. Ronse y J-M Rey]. Paris: Gallimard.

Bataille, Georges (1972) Sobre Nietzsche, voluntad de suerte, [Traducción de Fernando Savater]. Madrid: Taurus.

\footnotetext{
${ }^{7}$ Frase architrillada en cualquier trabajo de referencia que rescata un texto paradójicamente nunca traducido al castellano y publicado originalmente por Critique t.19, 1963, como número homenaje.

${ }^{8}$ Para comprobar la influencia que Bataille marcó sobre Foucault y el reconocimiento de éste basta pasearse por las páginas de El yo minimalista, sus últimas conversaciones autoreferenciales. Foucault (1996) El yo minimalista. Buenos Aires: La Marca.
} 
Bataille, Georges (1975)Teoría de la religión [Texto establecido por Thadée Klossowski; traducción de Fernando Savater] Madrid: Taurus.

Bataille, Georges (1977) Madame Edwarda [Introducción y traducción de Salvador Elizondo]. México: Premiá.

Bataille, Georges (1997) Las lágrimas de Eros [Introducción de J. M. Lo Duca; traducción de David Fernández] Barcelona: Tusquets.

Bataille, Georges (2001) La felicidad, el erotismo y la literatura, Ensayos 1944/1961. Buenos Aires: Adriana Hidalgo.

Benjamin, Walter (1971) Angelus novus. Buenos Aires: Edhasa.

Bergson, Henri (1966) Introducción a la metafísica ; y La intuición filosófica. Buenos Aires: Siglo XX.

Borges, Jorge Luis (1957) Ficciones. Buenos Aires: Emecé.

Engelmann, Paul (1967) Letters for Ludwig Wittgenstein. Oxford: Oxford University Press.

Foucault, Michel (1968) Las palabras y las cosas. Buenos Aires: Siglo XXI.

Guide, André (1951) Corydon. París: Gallimard.

Heidegger, Martín (1995) Caminos de bosque. Madrid: Alianza.

Klossowski, Pierre (1970) Sade, mi prójimo. Buenos Aires: Sudamericana.

Lezama Lima, Luis (1947) Límites de la literatura. Revista Orígenes № 16, La Habana.

Martínez Estrada, Ezequiel (1940) La cabeza de Goliat. Buenos Aires: Emecé.

Martínez Estrada, Ezequiel (1950) Apostillas para la re-lectura de Nietzsche. Revista Sur № 192-194, Buenos Aires.

Murena, Héctor (1950) Nietzsche y la desuniversalización del mundo. Revista Sur No 192-194, Buenos Aires.

Nietzsche, Friedrich (1987) Ecce Homo. Madrid: Alba.

Nietzsche, Friedrich (2001) La voluntad de poder. Madrid: Edaf.

Rodríguez García, José Luis (1994) Verdad y escritura. Barcelona: Anthropos.

Sartre, Jean Paul (1986) Cartas a Castor. Barcelona: Edhasa.

Wittgenstein, Ludwig (1991) Diarios secretos. Madrid: Alianza.

\section{Formato de citación}

Butti, D. (2004). El espíritu acefálico y la imposibilidad de decirlo todo. Athenea Digital, 4. Disponible en http://antalya.uab.es/athenea/num6/butti.pdf 




\section{Este texto está protegido por una licencia Creative Commons.}

Usted es libre de copiar, distribuir, exhibir y comunicar la obra bajo las siguientes condiciones:

Reconocimiento: Vd. debe reconocer y dar crédito al autor original.

NoComercial. Vd. no puede utilizar esta obra para fines comerciales.

NoDerivados. Vd. no puede alterar, transformar, o añadir nada a esta obra.

\section{Resumen de licencia}

Texto completo de la licencia 